\title{
Fator facilitador ou barreira para cidadãos acessarem e-serviços: o papel do texto em governo eletrônico
}

\author{
Facilitating factor or barrier for citizens to access e-services: \\ the role of text in e-Government
}

\author{
FISCHER, Heloisa \\ PUC-Rio Laboratório de Ergonomia e Usabilidade de Interfaces (LEUI), Mestranda \\ helofischer@gmail.com \\ MONT'ALVÃO, Claudia \\ PUC-Rio Laboratório de Ergonomia e Usabilidade de Interfaces (LEUI), DSc \\ cmontalvao@puc-rio.br \\ RODRIGUES, Erica dos Santos \\ PUC-Rio Laboratório de Psicolinguística e Aquisição da Linguagem (LAPAL), DSc \\ cmontalvao@puc-rio.br
}

\section{RESUMO}

Facilitar o acesso a serviços digitais é um grande desafio para governos em todo o mundo e o Brasil é um dos países que enfrentam baixo nível de adoção de serviços públicos digitais (e-serviços). Pesquisas nacionais e internacionais têm investigado a questão sob variadas perspectivas, sem questionar o papel que o texto pode exercer na compreensão das informações e, eventualmente, influir na adoção dos eserviços. Textos do setor público costumam ser escritos no estilo conhecido como "burocratês", apresentando aspectos linguísticos que dificultam a leitura. O objetivo deste artigo é discutir como a compreensibilidade textual pode contribuir para a facilitação de acesso a serviços públicos digitais brasileiros, apresentando pesquisa documental e revisão bibliográfica sobre os conceitos de interação em e-gov, valor público (com foco no design do e-serviço), burocratês e linguagem simples. O artigo aponta características linguísticas de um fragmento de texto sobre um e-serviço no portal GOV.BR. Concluiu-se que a técnica de redação Linguagem Simples (Plain Language), usada em e-gov de vários países e ainda incipiente no Brasil, tem sinergia com a proposta de atender as necessidades do usuário. Intervenções utilizando Linguagem Simples poderiam potencialmente contribuir com o atributo "facilidade de uso" buscado por gestores públicos ao projetar e-serviços.

Governo eletrônico; Compreensibilidade textual; Burocratês; Linguagem Simples; Valor Público 


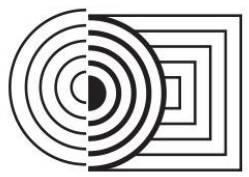

\section{$17^{\circ}$ ERGODESIGN \& USIHC 2019 \\ PUC-Rio, 11 a 13 de dezembro \\ Rio de Janeiro, RJ, Brasil}

$17^{\circ}$ Ergodesign - Congresso Internacional de Ergonomia e Usabilidade de Interfaces Humano Tecnológica: Produto, Informações Ambientes Construídos e Transporte

$17^{\circ}$ USIHC - Congresso Internacional de Ergonomia e Usabilidade

de Interfaces Humano Computador

Facilitating access to digital services is a major challenge for governments worldwide, and Brazil is one of the countries with low levels of adoption of digital public services (e-services). National and international research have investigated this issue from several perspectives, without questioning the role that text can play in understanding the information, and, eventually, influencing the adoption of e-services. Public sector texts are usually written in the style known as bureaucratese or Gobbledygook, which has linguistic aspects that make reading difficult. This article aims to discuss how textual comprehensibility can contribute to facilitating access to Brazilian digital public services. It presents a documental research and literature review on e-government interaction, public value (focusing on the design of e-services), bureaucratese and Plain Language. It also points out linguistic characteristics of a text fragment from an e-service in the GOV.BR website. The study concludes that the Plain Language writing technique, employed in foreign e-government but still incipient in Brazil, may work in synergy with the goal of meeting user needs. Interventions using Plain Language could potentially contribute to the "ease of use" attribute pursued by public managers when designing e-services.

E-Government; Textual comprehensibility; Bureaucratese; Plain Language; Public Value

\section{INTRODUÇÃO}

Um dos desafios atuais da transformação digital do setor público é facilitar o acesso a serviços em governo eletrônico (BRASIL, 2018b, p.24; UNITED NATIONS, 2018, p.30). Entende-se por governo eletrônico, ou e-gov, o uso das tecnologias de informação e comunicação na administração pública (COMITÊ, 2018, p.98). Neste contexto, a interação dos cidadãos ocorre em plataformas digitais e os serviços públicos passam a ser chamados de "e-serviços". Muitos países enfrentam baixos níveis de adoção de e-serviços pelos usuários e buscam investigar os motivos (RANA E DWIVEDI, 2015). No Brasil, os e-servicos federais atendem oito categorias de usuários $^{1}$ (BRASIL, 2018).

Estudos sobre a facilitação de acesso a e-serviços partem de variadas perspectivas. Há os que consideram prioritário atender as expectativas que os cidadãos têm ao interagir com a governança digital. Tal perspectiva vem sendo adotada em trabalhos recentes sobre valor público (AL-HURJAN ET AL, 2015; LOPES, 2016; LOPES, LUCIANO E MACADAR 2018a e 2018b; JORDAN, 2019). Nestes trabalhos, o design do e-serviço é apontado como um dos fatores direcionadores de valor público. Projetar e-serviços orientados aos usuários, facilitando o acesso e entregando conveniência, constitui uma das formas de governos criarem valor público.

A informação textual é um elemento básico na prestação de serviços públicos. Textos de eserviços - assim como os textos de governo eletrônico e os da comunicação pública em geral costumam ser redigidos em um estilo dicionarizado no português brasileiro como "burocratês" (HOUAISS, 2001, pag. 532). Trata-se de uma escrita que diverge do tipo de linguagem que é familiar aos usuários. Apesar de ser essencial para a compreensão dos e-serviços, o texto não vem recebendo espaço nas pesquisas sobre criação e percepção de valor público.

\footnotetext{
${ }^{1}$ Os oito tipo de usuários são: Cidadãos e famílias; Estrangeiros(as); Empresas privadas; Empresas públicas ou de economia mista; Pessoas jurídicas de direito privado sem fins lucrativos; Fundações e autarquias de direito privado; Órgãos da administração direta; Estados e municípios.
} 


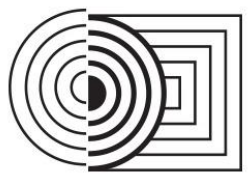

\section{$17^{\circ}$ ERGODESIGN \& USIHC 2019 \\ PUC-Rio, 11 a 13 de dezembro \\ Rio de Janeiro, RJ, Brasil}

$17^{\circ}$ Ergodesign - Congresso Internacional de Ergonomia e Usabilidade de Interfaces Humano Tecnológica: Produto, Informações Ambientes Construídos e Transporte

$17^{\circ}$ USIHC - Congresso Internacional de Ergonomia e Usabilidade

de Interfaces Humano Computador

A técnica de redação internacionalmente conhecida como Plain Language (Linguagem Simples) oferece um contraponto à redação em burocratês. Ao longo de décadas, diversos atores sociais compilaram orientações para elaborar textos claros, concisos e objetivos, compondo um movimento pelo direito de entender informações de interesse público. A linguagem simples privilegia vocabulário familiar ao cidadão comum e constrói frases com estrutura fácil de ler. Vem sendo usada no governo eletrônico de alguns países, como Reino Unido e Estados Unidos, mas ainda é incipiente no Brasil (FISCHER, 2018).

O objetivo deste artigo é discutir como a compreensibilidade textual pode contribuir para a facilitação de acesso a serviços públicos digitais brasileiros. Para tal, busca fundamentação nos conceitos de valor público, interação em e-gov, burocratês e Linguagem Simples.

O trabalho está organizado da seguinte forma. Esta primeira seção introduz o tema e contextualiza o escopo do artigo. A seção 2 debruça-se sobre o estágio de digitalização de serviços públicos do governo federal brasileiro e aborda barreiras para interagir em e-gov. Apresenta o conceito de valor público, enfatizando questões relativas ao design do e-serviço.

$\mathrm{Na}$ seção 3, o artigo discorre sobre os aspectos linguísticos do burocratês, discute o seu impacto na compreensibilidade textual e exemplifica com um fragmento de texto sobre serviço no portal gov.br. Também apresenta características da técnica de redação da Linguagem Simples, indica os países que a utilizam em e-gov e aponta as iniciativas hoje existentes no Brasil.

Por fim, o artigo conclui com uma breve síntese da discussão proposta e com a indicação de próximos passos.

\section{INTERAÇÃO EM E-GOV E VALOR PÚBLICO}

\subsection{Estágio de digitalização dos serviços públicos federais}

O processo de digitalização da administração pública federal brasileira está completando vinte anos $^{2}$. O período acumula marcos regulatórios, padrões normativos, desenvolvimento de plataformas e pesquisas de avaliação, entre outras ações. O conjunto de esforços mostra resultado. A mais recente edição do Índice de Desenvolvimento de E-gov, feito pela ONU, coloca o Brasil na 44aㅡ posição entre os 193 países-membro da entidade (UNITED NATIONS, 2018). Na edição anterior, dois anos antes, ocupávamos o 51ํlugar.

\footnotetext{
2 Tudo começou em abril de 2000, com o decreto do então presidente Fernando Henrique Cardoso que criou um grupo de trabalho interministerial para "examinar e propor políticas, diretrizes e normas relacionadas com as novas formas eletrônicas de interação" (BRASIL, 2000a). Em outubro do mesmo ano, o Comitê Executivo de Governo Eletrônico era instituído por decreto presidencial (BRASIL, 2000b).
} 
A maioria dos serviços públicos no Brasil é fornecida por estados e municípios (OECD, 2018, p. 22). Ainda assim, os serviços prestados em nível federal são bastante significativos. Quando este artigo era escrito, em setembro de 2019, o site gov.br agregava um total de 3.298 serviços em 182 órgãos federais (Figura 1).

Figura 1: Painel de monitoramento de serviços (imagem capturada em 12/09/2019). Fonte: Portal gov.br.

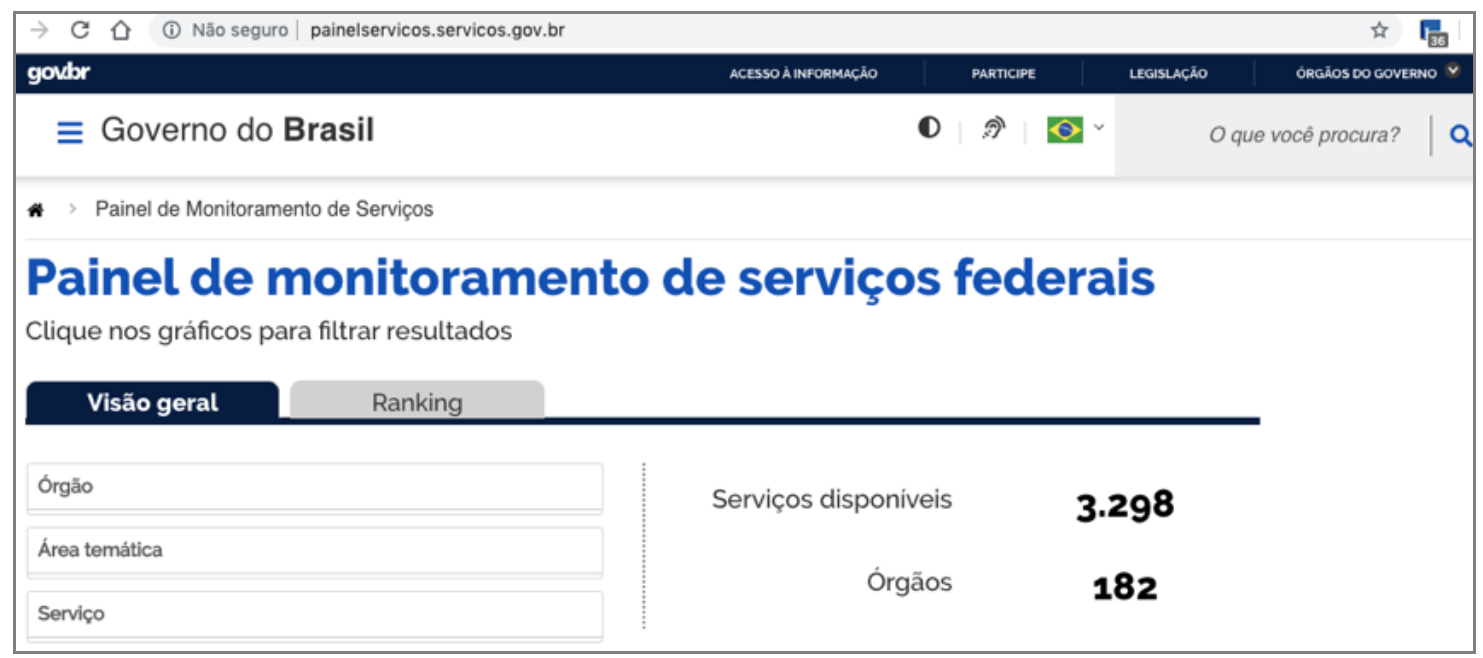

A facilitação de acesso a serviços digitais é um dos principais desafios para aprimorar a efetividade das ações de e-gov em âmbito federal (BRASIL, 2018b, p.24). Uma recente pesquisa da Escola Nacional de Administração Pública categorizou cinco estágios de digitalização dos serviços e indicou os seus respectivos percentuais ${ }^{3}$ :

- Nenhum (15,6\%): Totalmente prestado por presença física, sem disponibilizar informações em plataformas digitais;

- Informativo (8,8\%): Acesso a informações sobre o serviço em plataformas digitais. A prestação é totalmente presencial;

- Parcial (44,1\%): Pelo menos uma etapa do processo de atendimento ocorre por meio digital;

- Digital (24\%): Todas as interações são realizadas por meio digital, mas requer alguma ação humana por parte do órgão;

- Autosserviço (7,4\%): Completamente automatizado. Todo processamento é realizado por sistemas de informação (BRASIL, 2018a, p.64).

A Política Brasileira de Governança Digital determina o autosserviço como a forma prioritária de prestação de serviços públicos em meio digital (BRASIL, 2016a). Ou seja, a meta do e-gov federal é fazer com que o maior número possível de serviços seja acessado sem requerer

\footnotetext{
${ }^{3}$ A pesquisa da Enap analisou 1.740 serviços de 85 órgãos federais.
} 


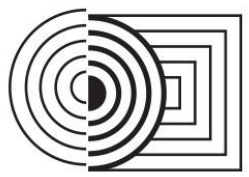

\section{$17^{\circ}$ ERGODESIGN \& USIHC 2019 \\ PUC-Rio, 11 a 13 de dezembro \\ Rio de Janeiro, RJ, Brasil}

$17^{\circ}$ Ergodesign - Congresso Internacional de Ergonomia e Usabilidade de Interfaces Humano Tecnológica: Produto, Informações Ambientes Construídos e Transporte

$17^{\circ}$ USIHC - Congresso Internacional de Ergonomia e Usabilidade

de Interfaces Humano Computador

qualquer tipo de intermediação humana. Os percentuais aferidos pela pesquisa da Enap mostram que e-serviços com completa automatização ainda são a minoria, apesar de serem uma prioridade administrativa.

\subsection{Facilitação de acesso a e-serviços e compreensibilidade textual}

Se no autosserviço a possibilidade de esclarecer dúvidas por meio de interações humanas é totalmente eliminada, nos demais estágios de digitalização - informativo, parcial e digital -, as chances de o usuário receber explicação pessoal para as suas indagações são cada vez mais reduzidas ou tendem a desaparecer. Esta conjuntura imprime a necessidade de escrever informações e instruções sobre e-serviços de modo a minimizar as dúvidas.

Apesar disso, os textos governamentais continuam sendo redigidos no estilo de escrita típico da burocracia pública, só compreensível por técnicos e especialistas. Escrever informações e instruções sobre e-serviços de forma clara, concisa e objetiva, em um linguajar familiar aos cidadãos, com palavras que qualquer leitor conheça, requer uma mudança estrutural na comunicação pública.

Neste sentido, estudos sobre facilitação de acesso a e-serviços vêm incentivando os governos a realizarem transformações com vistas a atender melhor a população.

A Estratégia de Governança Digital observa que o principal desafio da transformação digital de governos não é tecnológico, consistindo em vez disso em "direcionar esforços e coordenar mudanças estruturais na organização da sociedade e do governo" (BRASIL 2018b, p.5, grifo das autoras).

O estudo "Revisão do Governo Digital do Brasil", conduzido pela Organização para a Cooperação e Desenvolvimento Econômico (OCDE), reiterou a importância de a governança brasileira mudar a orientação e ir ao encontro das necessidades do usuário de e-serviços:

A realização da priorização de uma sólida política de entrega de serviços digitais permitirá ao governo brasileiro mudar o panorama do país e deixar gradativamente de ser centrado nas instituições e em suas práticas para que a prestação de serviços seja orientada ao usuário (OECD, 2018, p.22, grifo das autoras).

Já a pesquisa da Escola Nacional de Administração Pública sobre serviços públicos prestados pelo governo federal concluiu o seguinte:

A partir dos dados levantados nesta pesquisa, pode-se inferir que uma política pública de construção do e-government, no Brasil, deve dar conta de um processo complexo que respeite um fluxo orientado à prestação de serviços para a cidadania, ao mesmo tempo em que mude a estrutura das burocracias e os modelos de gestão pública. (BRASIL, 2018a, p.75, grifo das autoras)

A necessidade de facilitar o acesso a serviços públicos digitais fornece condições para que o estilo de texto em e-gov seja transformado, passando a priorizar as necessidades dos usuários e o fortalecimento da cidadania. 


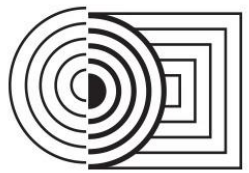

\section{$17^{\circ}$ ERGODESIGN \& USIHC 2019 \\ PUC-Rio, 11 a 13 de dezembro \\ Rio de Janeiro, RJ, Brasil}

$17^{\circ}$ Ergodesign - Congresso Internacional de Ergonomia e Usabilidade de Interfaces Humano Tecnológica: Produto, Informações Ambientes Construídos e Transporte

$17^{\circ}$ USIHC - Congresso Internacional de Ergonomia e Usabilidade

de Interfaces Humano Computador

\subsection{Barreiras à interação em e-gov e compreensibilidade textual}

Barreiras à interação em e-gov são um problema global e multifacetado que agrava a segregação digital (digital divide) em todos os países. Inicialmente, a segregação digital era relacionada à falta de acesso à internet e a computadores. Com o passar do tempo, o avanço da tecnologia trouxe outros agravantes da segregação, como a velocidade de conexão, a qualidade dos equipamentos e o conhecimento sobre como usá-los.

A Organização das Nações Unidas esquematiza treze categorias de digital divide que dificultam o acesso a e-serviços e afetam a participação cidadã (UNITED NATIONS, 2018, p.34). A lista inclui barreiras geográficas, por localização em áreas rurais ou remotas com qualidade de conexão ruim; barreiras de idade, sendo os idosos a faixa etária mais prejudicada pela falta de competências digitais; e até as barreiras de conteúdo, levando em conta os países que têm idiomas locais e só disponibilizam os seus e-serviços na língua oficial.

A ONU considera a sua categorização de barreiras agravadoras da segregação digital apenas um apanhado inicial. Por conseguinte, estimula a comunidade internacional a expandi-lo.

Cabe mencionar que, há décadas, o movimento internacional plain language aponta o estilo de escrita típico da burocracia governamental como uma barreira que dificulta a comunicação de informações de interesse público (FISCHER, 2018). As características linguísticas do burocratês e a gradativa adoção de linguagem simples em governos eletrônicos internacionais serão detalhados na próxima seção.

Nesse sentido, poderia ser possível considerar a linguagem burocrática usada pelo setor público como uma barreira à interação em e-gov e um agravante da segregação digital. Por prejudicar a compreensão textual sobre os e-serviços, o burocratês compromete-lhes o acesso e afeta o pleno exercício da cidadania.

$\mathrm{Na}$ medida em que a ONU recomenda que governos comprometam-se a disponibilizar serviços públicos 'a todos, sem deixar ninguém para trás' (UNITED NATIONS, 2018, xxiii), cabem ser consideradas ações que atenuem as barreiras de compreensão textual impostas pelo burocratês. Lopes, Macadar e Luciano (2018) advertem que 'inovação em governo só faz sentido se entrega valor às pessoas'.

\subsection{Valor público e design de e-serviços}

Valor público foi um termo cunhado na área de administração pelo pesquisador americano Mark Moore, da Universidade de Harvard, em 1995. À época, a perspectiva New Public Management (NPM) promovia a ideia de gerir governos como empresas privadas: terceirizar e privatizar, reduzir custo e pessoal, transformar servidores públicos em gerentes e encarar os cidadãos como clientes. Moore introduziu o conceito de valor público como contraponto à NPM, promovendo a ideia de que gestores públicos deveriam procurar produzir valor público (JORDAN, 2019).

Lopes, Luciano e Macadar (2018a) realizaram uma análise bibliométrica da produção científica sobre valor público e concluíram que o conceito conectou-se à pauta de governo digital a partir de 2003, com um aumento significativo de publicações a partir de 2015. Mas as pesquisas ainda são poucas, especialmente no Brasil. Por não existir uma definição canônica do termo, as pesquisadoras brasileiras analisaram definições presentes em vinte trabalhos internacionais e 


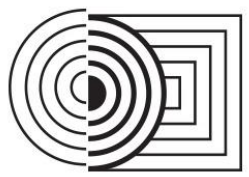

\section{$17^{\circ}$ ERGODESIGN \& USIHC 2019 \\ PUC-Rio, 11 a 13 de dezembro \\ Rio de Janeiro, RJ, Brasil}

$17^{\circ}$ Ergodesign - Congresso Internacional de Ergonomia e Usabilidade de Interfaces Humano Tecnológica: Produto, Informações Ambientes Construídos e Transporte

$17^{\circ}$ USIHC - Congresso Internacional de Ergonomia e Usabilidade de Interfaces Humano Computador

propuseram o seguinte conceito: "Valor público é o valor produzido pelo governo, que é percebido pelos cidadãos e criado na adoção dos serviços digitais" (ibid, p. 216).

A conceituação de Kelly et a.I (2002), ponto de partida do artigo mais citado pelo levantamento bibliométrico e referência recorrente em muitas publicações sobre o tema, enfatiza o papel central que cabe ao cidadão:

Valor público refere-se ao valor criado pelo governo através de serviços, legislação e outras ações. Numa democracia, este valor é definido em última instância pelo próprio público. O valor é determinado pelas preferências dos cidadãos, expressas em uma variedade de meios e refletidas nas decisões dos políticos eleitos. [...] Como regra geral, o que mais os cidadãos valorizam tende a se encaixar em três categorias: resultados, serviços e confiança (KELLY ET AL. 2002, p. 4, tradução das autoras) ${ }^{4}$

Considerando a baixa adoção de e-serviços por cidadãos, Al-Hujran et al. (2015, p. 189) frisam "a importância de compreender os variados fatores que podem influenciar a adoção de serviços digitais por parte dos cidadãos". Este ponto de vista é corroborado por Lopes:

Os governos devem aumentar a conscientização dos cidadãos sobre o valor do uso dos e-serviços e melhorá-los à luz das necessidades dos cidadãos. Assim, a compreensão dos fatores que influenciam a adoção dos e-serviços pelos cidadãos passa a ser uma questão política relevante e deve estimular a ampliação do conhecimento nesse domínio para elaboração de políticas públicas e como insumo para melhoria do design dos eserviços (LOPES, 2016, p.57)

Lopes (2016) categorizou quatro fatores direcionadores para criação de valor público em eserviços: processo colaborativo, design do e-serviço, abertura governamental e confiança dos cidadãos. Por design do e-serviço, a autora entende "os aspectos relacionados ao projeto, concepção e desenho até a sua efetiva prestação do e-serviço, na perspectiva do cidadão". Em trabalho posterior, decorrente da mesma pesquisa, Lopes, Luciano e Macadar (2018b) elencaram as seguintes variáveis observáveis no design do e-serviço: orientação para o usuário, facilidade de uso e usabilidade.

Em relação à facilidade de uso, Al-Hujran et al. concluíram que:

O valor público percebido e a facilidade de uso percebida mostraram-se determinantes das atitudes dos cidadãos em relação ao uso de serviços de governo eletrônico, sugerindo que o governo deveria tornar os governos eletrônicos mais valiosos e usáveis (AL-HUJRAN ET AL., 2015, p. 198, tradução das autoras) ${ }^{5}$

Tendo em conta que e-serviços são acessados a partir de informações e instruções escritas nas interfaces digitais, pode-se entender que o atributo "facilidade de uso" abarca o texto. Mas os trabalhos aqui citados não mencionam aspectos textuais associados à facilidade de uso.

\footnotetext{
${ }^{4}$ No original em inglês: "Public value refers to the value created by government through services, lawsregulation and other actions. In a democracy this value is ultimately defined by the public themselves. Value isdetermined by citizens' preferences, expressed through a variety of means andrefracted through the decisions of elected politicians. [...] As a general rule the key things which citizens value tend to fall into three categories:outcomes, services and trust."

5 No original em inglês: "Perceived public value and perceived ease of use were shown to be significant determinants of citizen's atitudes toward using e-government services, sugegsting that the government should make e-governments more valuable and usable."
} 


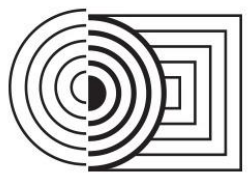

\section{$17^{\circ}$ ERGODESIGN \& USIHC 2019 \\ PUC-Rio, 11 a 13 de dezembro \\ Rio de Janeiro, RJ, Brasil}

$17^{\circ}$ Ergodesign - Congresso Internacional de Ergonomia e Usabilidade de Interfaces Humano Tecnológica: Produto, Informações Ambientes Construídos e Transporte

$17^{\circ}$ USIHC - Congresso Internacional de Ergonomia e Usabilidade

de Interfaces Humano Computador

A próxima seção apresentará características linguísticas do burocratês e exemplificará a sua complexidade. Também apresentará características da redação em linguagem simples, indicará os países que adotam essa técnica em e-gov e abordará o contexto de aplicação da linguagem simples em governo eletrônico brasileiro.

\section{BUROCRATÊS E LINGUAGEM SIMPLES}

\subsection{Características linguísticas do burocratês}

Na maioria dos países, inclusive no Brasil, textos em e-gov costumam seguir o mesmo padrão de linguagem burocrática característico da comunicação pública. $O$ burocratês é marcado pela escrita floreada, herdeira da linguagem jurídica, com estrutura sintática complexa, pseudoerudita, vocabulário pouco familiar e alta carga informacional. De tão complexo e obscuro, este estilo de redação foi classificado como "obscuranto" em documentos oficiais da União Europeia e tornou-se verbete do Bloomsbury Business \& Management Dictionary.

Em um estudo pioneiro nos anos 1980, Neide Rodrigues de Souza Mendonça assim definiu o estilo:

A linguagem burocrática - burocratês, prosa institucional ou linguagem da burocracia - é uma subvariedade escrita da língua materna, usada pelos membros da administração durante o seu trabalho. É encontrada nos documentos que emanam das instituições públicas (municipais, estaduais e federais) e privadas. [...] O psicolinguista Frank Smith afirma que, algumas vezes, a linguagem usada por médicos, advogados e burocratas é de difícil compreensão e que essa incompreensibilidade é voluntariamente criada." (MENDONÇA, 1987, p. 11)

Mendonça acrescenta que os traços específicos do burocratês "podem ser evidenciados no léxico e em construções gramaticais especiais" (ibidem, p. 12). Maria Inês Matoso Silveira observa que o uso de fórmulas arcaicas e empoladas "faz o burocratês parecer uma linguagem para iniciados, de caráter excludente". E adverte para os problemas que causa à compreensibilidade

dos

textos:

De fato, além do uso de terminologias técnicas específicas, a linguagem burocrática, quando revestida de suas tradicionais características estilísticas, se transforma em um sério problema de compreensão para as pessoas externas às suas comunidades discursivas, ou seja, para as pessoas que não estão diretamente ligadas aos setores da burocracia administrativa em instituições públicas e particulares. (SILVEIRA, 2008, p. 224)

Para Silveira (2008), a formalidade e a impessoalidade são as principais marcas linguísticas do burocratês. A formalidade expressa-se na escolha de vocativos, pronomes de tratamento, fórmulas de polidez, fórmulas de saudação e rebuscamento de vocabulário, com eufemismos, termos abstratos, jargão burocrático e arcaísmo. A impessoalidade expressa-se principalmente no uso de voz passiva, nominalizações e o evitamento da referência anafórica pronominal. 
$17^{\circ}$ ERGODESIGN \& USIHC 2019

PUC-Rio, 11 a 13 de dezembro Rio de Janeiro, RJ, Brasil $17^{\circ}$ Ergodesign - Congresso Internacional de Ergonomia e Usabilidade de Interfaces Humano Tecnológica: Produto, Informações Ambientes Construídos e Transporte

$17^{\circ}$ USIHC - Congresso Internacional de Ergonomia e Usabilidade de Interfaces Humano Computador

Trabalhos anteriores já problematizaram o burocratês na governança digital brasileira, recomendando a linguagem simples (BARBOSA e NUNES, 2007; BARBOZA, 2010). Também já foi avaliada a compreensibilidade textual em e-gov antes e depois da reescrita em linguagem simples, usando o Teste de Cloze (MARTINS e FILGUEIRAS, 2007).

À constatação de todos os pesquisadores aqui reunidos, sobre o burocratês ser inacessível à maioria dos cidadãos brasileiros, acrescentem-se os dados de alfabetismo da nossa população:

- $\quad 29 \%$ de analfabetos funcionais: não sabem ler (analfabetos) ou só localizam informações explícitas e literais, em textos muito simples (nível rudimentar);

- $34 \%$ em nível de alfabetismo elementar: sob certas condições, selecionam informações em textos de extensão média e fazem pequenas inferências;

- $25 \%$ em nível intermediário: localizam informação expressa de forma literal e realizam pequenas inferências;

- $12 \%$ em nível proficiente: elaboram textos de maior complexidade (AÇÃO, 2018).

Os dados apresentados nesta subseção reafirmam a relevância de textos sobre serviços públicos digitais serem orientados para o usuário - seja ele o cidadão ou um dos demais tipos mencionados no rodapé da primeira página deste artigo.

A Figura 2 exemplifica as dificuldades que o burocratês coloca à compreensibilidade de informações sobre serviços públicos. Trata-se de um fragmento do texto informativo sobre 0 serviço "Aquisição de repelente para gestante inscrita no programa Bolsa Família", disponível no portal gov.br. Neste serviço, os usuários são as prefeituras.

Figura 2: Texto informativo sobre aquisição de repelente para grávidas cadastradas no Bolsa Família (imagem capturada em 12/09/2019). Fonte: Portal gov.br.

\section{- O que é?}

A aquisição e distribuição de repelentes, realizada pelo Ministério da Saúde, com recursos relativos ao crédito extraordinário em favor do Ministério do Desenvolvimento Social e Agrário (Lei n’ 13.310, de 7 de julho de 2016), visa oferecer às gestantes integrantes de familias beneficiárias do Programa Bolsa Familia (PBF) proteção individual contra as principais arboviroses urbanas Dengue, Zika e Chikungunya-, transmitidas pelo mosquito Aedes Aegypti e comprovadamente relacionadas à ocorrência de microcefalia em nascituros.

O fragmento é composto por uma única sentença de 73 palavras, muito acima do limite de 20 a partir do qual as diretrizes internacionais de linguagem simples recomendam reescrever 0 período. 


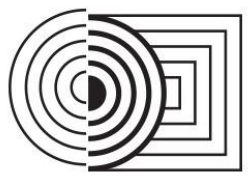

\section{$17^{\circ}$ ERGODESIGN \& USIHC 2019 \\ PUC-Rio, 11 a 13 de dezembro \\ Rio de Janeiro, RJ, Brasil}

$17^{\circ}$ Ergodesign - Congresso Internacional de Ergonomia e Usabilidade de Interfaces Humano Tecnológica: Produto, Informações Ambientes Construídos e Transporte

$17^{\circ}$ USIHC - Congresso Internacional de Ergonomia e Usabilidade

de Interfaces Humano Computador

O sujeito, que tem como núcleo "aquisição e distribuição", é longo e modificado por sintagmas sucessivos e encadeados, implicando alto custo para a memória de trabalho. Inclui ainda o uso de uma forma reduzida de passiva ("realizada pelo Ministério da Saúde") e termina com uma referência extratextual à lei que fundamenta o referido benefício.

O objeto direto oracional (iniciado por "oferecer às gestantes...") também se caracteriza pela longa extensão e por envolver formas passivas ("transmitidas" e "relacionadas"). O uso de palavras pouco conhecidas também chama a atenção, com destaque para os termos "arborivoses", "microcefalia" e "nascituros".

As principais diretrizes da técnica da linguagem simples serão listadas na subseção a seguir.

\subsection{Linguagem Simples (Plain Language): características da técnica de redação}

Linguagem simples (Plain Language) é uma técnica de redação e um movimento social com força em vários países. Também é conhecida em português como linguagem clara ou linguagem cidadã. Como causa social, defende o direito de entender os textos de interesse público (FISCHER, 2018). Como técnica de redação, segue uma série de diretrizes de escrita, design da informação e usabilidade para facilitar a leitura de textos (SCHRIVER, 2017).

O site da Plain Language Association International-PLAIN (Associação Internacional de Linguagem Clara-PLAIN), entidade com sede no Canadá, oferece a seguinte definição, já traduzida para o português:

"Uma comunicação está em linguagem clara quando o texto, a estrutura e o design são tão claros que o público-alvo consegue encontrar facilmente o que procura, compreender o que encontrou e usar essa informação. Usar linguagem clara significa priorizar o leitor. Descobrir o que os leitores querem saber, de que informação precisam, e ajudá-los a alcançar suas metas. O objetivo é que o leitor consiga compreender um documento escrito em linguagem clara logo na primeira leitura. Mas linguagem clara não é só uma questão de linguagem. Também inclui design, diagramação e muito mais." (PLAIN - grifo das autoras)

A centralidade que a linguagem simples atribui ao papel do leitor está em sintonia com o atributo "orientação ao usuário" que embasa o referencial teórico sobre valor público e, especificamente, em sintonia com o fator direcionador "design do e-serviço: facilidade de uso".

Quanto às características da redação em linguagem simples, Cutts (2013) propõe o uso de 25 diretrizes. Harris, Kleinman e Mowat (2010) sintetizaram o trabalho de Cutts em doze diretrizes, assim agrupadas:

\section{- Estilo e gramática}

1. Escreva frases com extensão média de 15 a 20 palavras.

2. Use palavras que o leitor provavelmente entenderá.

3. Use apenas o número necessário de palavras.

4. Prefira a voz ativa, a menos que tenha uma boa razão para usar a passiva.

5. Use verbos claros e vívidos para expressar ações. 
$17^{\circ}$ ERGODESIGN \& USIHC 2019

PUC-Rio, 11 a 13 de dezembro

Rio de Janeiro, RJ, Brasil $17^{\circ}$ Ergodesign - Congresso Internacional de Ergonomia e Usabilidade de Interfaces Humano Tecnológica: Produto, Informações Ambientes Construídos e Transporte

$17^{\circ}$ USIHC - Congresso Internacional de Ergonomia e Usabilidade de Interfaces Humano Computador

6. Divida o texto em tópicos.

7. Apresente seu assunto de modo claro e categórico sempre que possível.

8. Reduza ao mínimo as referências extratextuais.

9. Evite linguagem com marcadores de gênero.

10. Seja preciso na pontuação.

- Organização

11. Organize seu material de modo a ajudar o leitor a captar rapidamente as informações importantes e a se orientar com facilidade pelo texto.

\section{- Diagramação}

12. Dê às suas palavras uma apresentação visual clara e acessível.6

Pode-se concluir que a redação em linguagem simples tem o potencial de minimizar os problemas de compreensibilidade textual decorrentes do uso do burocratês em informações sobre serviços públicos digitais. Também pode-se inferir que existe uma paridade entre esta técnica de redação e os fatores

\subsection{O uso de linguagem Simples em e-gov internacionais e no Brasil}

Há registros de uso de plain language na administração pública dos Estados Unidos e do Reino Unido já nos anos 1940, em grande parte por iniciativa dos próprios servidores. A partir dos anos 1970, o movimento expandiu-se para outros países. Dos anos 2000 em diante, a transformação digital de governos impulsionou o uso da linguagem simples mesmo em países com população altamente escolarizada (FISCHER, 2018, p. 21-36)

Atualmente, há pelo menos seis países que usam linguagem simples em e-gov. Estados Unidos, Reino Unido, Canadá, Austrália, Nova Zelândia e Colômbia. A seguir, os endereços na internet onde constam as suas diretrizes para escrita em linguagem simples:

- Estados Unidos: plainlanguage.gov/guidelines/

- Reino Unido: gov.uk/guidance/content-design/writing-for-gov-uk

- Canadá: canada.ca

- Austrália, guides.service.gov.au

- Nova Zelândia: digital.govt.nz

- Colômbia: as diretrizes de uso constam do Guía de lenguaje claro para servidores públicos de Colombia, disponível no site dnp.gov.co

No Brasil, as iniciativas para uso de linguagem simples na comunicação pública ainda são incipientes. Em 2016, dois entes públicos editaram guias com diretrizes de uso. O governo federal publicou a cartilha "Fugindo do 'burocratês': como facilitar o acesso do cidadão ao

\footnotetext{
${ }^{6}$ No original em inglês: Style and grammar: Make the average sentence length of 15-20 words; Use words your reader is likely to understand; Use only as many words as you need: Prefer the active voice unless there's a good reason for using the passive; Use clear, lively verbs to express actions; Use vertical lists to break up text; Put your points positively when you can; Reduce cross references to a minimum; Avoid sexist usage; Use accurate punctuation. Organisation: Organise your material in a way that helps the reader to grasp the important information early and to navigate through the document easily. Layout: Use clear layout to present your words in an easily accessible way.
} 


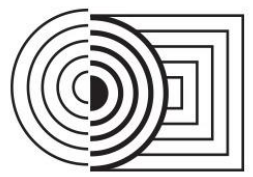

\section{$17^{\circ}$ ERGODESIGN \& USIHC 2019 \\ PUC-Rio, 11 a 13 de dezembro \\ Rio de Janeiro, RJ, Brasil}

$17^{\circ}$ Ergodesign - Congresso Internacional de Ergonomia e Usabilidade de Interfaces Humano Tecnológica: Produto, Informações Ambientes Construídos e Transporte

$17^{\circ}$ USIHC - Congresso Internacional de Ergonomia e Usabilidade

de Interfaces Humano Computador

serviço público" (BRASIL, 2016b). E o governo do estado de São Paulo lançou o guia "Orientações para adoção de linguagem clara", no âmbito de um projeto de boas práticas de governo aberto em cooperação com o Reino Unido.

Em abril de 2019, foi proposto Câmara Municipal de São Paulo um projeto de lei para instituir uma política municipal de linguagem clara (SÂO PAULO, 2019). O projeto ainda tramitava na casa quando este artigo era escrito.

\section{CONCLUSÃO E PRÓXIMOS PASSOS}

O artigo discutiu como a compreensibilidade textual pode contribuir para facilitar o acesso a eserviços, para mitigar a barreira à interação em e-gov e também para a criação e percepção de valor público na governança digital brasileira. O trabalho também problematizou a predominância dos textos de e-serviços escritos em burocratês por divergir do conceito de "orientação para as necessidades do usuário" - conceito que é basilar nos estudos sobre valor público, nas ações para reduzir o digital divide e no design de e-serviços. Por fim, o artigo mostrou que as diretrizes internacionais de linguagem simples apresentam alinhamento com o fator direcionador de valor público chamado "design do e-serviço" e têm potencial para contribuir com as variáveis "facilidade de uso" e "orientação para o usuário" em serviços públicos digitais.

Considerando que:

- E-govs devem ser "mais valiosos e usáveis" (AL-HUJRAN ET AL., 2015);

- A ONU recomenda que serviços públicos digitais estejam disponíveis "a todos, sem deixar ninguém para trás"(UNITED NATIONS, 2018, xxiii);

- $\quad 88 \%$ da população brasileira não elaboram textos de maior complexidade;

- Textos de e-serviços são predominantemente escritos em burocratês;

- Diversos países têm experiência de usar linguagem simples em textos de e-gov;

é possível inferir que adotar a linguagem simples no e-gov brasileiro pode vir a facilitar o acesso aos e-serviços e reduzir a segregação digital (digital divide). Assim, mostra-se oportuno avaliar o papel do estilo de linguagem na compreensibilidade textual de e-serviços, examinando aspectos linguísticos que facilitam ou dificultam a leitura.

A pesquisa na qual o presente trabalho está inserido pretende conduzir um experimento neste sentido. A pesquisa vem sendo desenvolvida no âmbito do meu mestrado no programa de pósgraduação em Design na Pontifícia Universidade Católica (PUC-Rio), dentro da linha Ergonomia e Usabilidade e Interação Humano-Computador. A pesquisa é de cunho exploratório e descritivo. Utiliza método misto sequencial em duas fases. A fase inicial qualitativa informará o experimento quantitativo de design fatorial que planeja avaliar o impacto da linguagem simples na compreensibilidade textual de um e-serviço do governo federal brasileiro. Além dos conceitos teóricos aqui expostos, a investigação em andamento na também fundamenta-se em conceitos da Psicolinguística sobre compreensibilidade textual, não contemplados no escopo deste artigo. 
$17^{\circ}$ ERGODESIGN

\& USIHC 2019

PUC-Rio, 11 a 13 de dezembro

Rio de Janeiro, RJ, Brasil $17^{\circ}$ Ergodesign - Congresso Internacional de Ergonomia e Usabilidade de Interfaces Humano Tecnológica: Produto, Informações Ambientes Construídos e Transporte

$17^{\circ}$ USIHC - Congresso Internacional de Ergonomia e Usabilidade

de Interfaces Humano Computador

\section{AGRADECIMENTOS}

O presente trabalho foi realizado com apoio da Coordenação de Aperfeiçoamento de Pessoal de Nível Superior - Brasil (CAPES) - Código de Financiamento 001.

\section{REFERÊNCIAS BIBLIOGRÁFICAS}

AL-HUJRAN, O.; AL-DEBEI, M. M.; CHATFIELD, A.; MIGDADI, M. The imperative of influencing citizen attitude toward e-government adoption and use. Computers in Human Behavior, [s.I.], 53, p.189-203, 2015.

BARBOZA, E. M. F; NUNES, E. M. A. A inteligibilidade dos websites governamentais brasileiros e o acesso para usuários com baixo nível de escolaridade. Inclusão Social, Brasília, v. 2, n. 2, p. 19-33. Abril/Set 2007. Disponível em: http://revista.ibict.br/inclusao/ article/view/1599. Acesso em: 12 set. 2019.

BARBOZA, E. M. F. A linguagem clara em conteúdos de websites governamentais para promover a acessibilidade de cidadãos com baixo nível de escolaridade. Inclusão Social, Brasília, v. 4, n. 1, p. 52-66, Jul/Dez 2010. Disponível em: http://revista.ibict.br/inclusao/ article/view/1644. Acesso em: 12 set. 2019.

BRASIL. Decreto de 3 de abril de 2000. Institui Grupo de Trabalho Interministerial para examinar e propor políticas, diretrizes e normas relacionadas com as novas formas eletrônicas de interação. Brasília, DF: Presidência da República, [2000]. Disponível em: http://www.planalto.gov.br/ccivil_03/DNN/2000/Dnn8917.htm. Acesso em: 12 set. 2019.

BRASIL. Decreto de 18 de outubro de 2000. Cria, no âmbito do Conselho de Governo, o Comitê Executivo do Governo Eletrônico, e dá outras providências. Brasília, DF: Presidência da República, [2000]. Disponível em: http://www.planalto.gov.br/ccivil 03/DNN/DNN9067. htm. Acesso $\quad$ em: $\quad 12$ set.

BRASIL, Decreto no 8.638 de 15 de janeiro de 2016. Institui a Política de Governança Digital no âmbito dos órgãos e das entidades da administração pública federal direta, autárquica e fundacional. Brasília, DF: Presidência da República, [2016]. Disponível em: http://www.planalto.gov.br/ccivil_03/_Ato2015-2018/2016/Decreto/D8638.htm. Acesso em: 29 ago. 2019.

BRASIL. Ministério do Planejamento, Desenvolvimento e Gestão. Fugindo do "burocratês": como facilitar o acesso do cidadão ao serviço público. Brasília, DF: Ministério do Planejamento, Desenvolvimento e Gestão, 2016. 11p. Disponível em: http://www.gespublica. gov.br/sites/default/files/documentos/linguagem cidada - versao final web.pdf. Acesso em: 12 set. 2019. 
BRASIL. Escola Nacional de Administração Pública. Pesquisa sobre serviços públicos de atendimento do governo federal. Brasília: Enap, 2018. 75 p. : il. -- (Cadernos Enap, 55). Disponível em: $\quad$ https://repositorio.enap.gov.br/handle/1/3217. Acesso em: 12 set. 2019.

BRASIL. Ministério do Planejamento, Desenvolvimento e Gestão. Estratégia de Governança Digital - EGD: Transformação Digital - cidadania e governo 2016-2019, versão revisada. Brasília, DF: Ministério do Planejamento, Desenvolvimento e Gestão, Secretaria de Tecnologia da Informação e Comunicação, 2018, 56 p. Disponível em: https://www.governodigital.gov.br/EGD/documentos/revisao-da-estrategia-de-governancadigital-2016-2019.pdf. Acesso em: 12 set. 2019.

COMITÊ GESTOR DA INTERNET NO BRASIL. TIC Governo Eletrônico 2017; Pesquisa sobre o uso das tecnologias de informação e comunicação no setor público brasileiro. São Paulo: Comitê Gestor da Internet no Brasil, 2018. PDF . Disponível em: https://cetic.br/media/docs/publicacoes/2/TIC_eGOV_2017_livro_eletronico.pdf. Acesso em: 12 set. 2019.

CUTTS, Martin. Oxford Guide to Plain English. Oxford: Oxford University Press, 2013.

FISCHER, Heloisa. Clareza em textos de e-gov, uma questão de cidadania. Rio de Janeiro: Com Clareza, 2018.

HARRIS, Lynda; KLEINMAN, Susan; MOWAT, Christine. Setting plain language standards. The Clarity Journal, Lansing, n. 64, p.16-25, November 2010. Disponível em: http://www.clarityinternational.net/wp-content/uploads/2015/05/Clarity-no-64-bookmarked1. pdf. Acesso em: 12 set. 2019.

HOUAISS, A.; VILLAR, M. de S. Dicionário Houaiss da Língua Portuguesa. Rio de Janeiro: Objetiva, 2001.

JORDAN, Martin. Creating public value through service design: Facilitation of humancentred service transformation in the city-state of Hamburg. Dissertação (Mestrado em Service Innovation \& Design) - Laurea University of Applied Sciences, Vantaa, Finlândia, 2019. Disponível em: https://www.theseus.fi/bitstream/handle/10024/227264/Thesis-MartinJordan. pdf?sequence=2\&isAllowed=y. Acesso em: 08 set. 2019.

KELLY, G.; MULGAN, G.; MUERS, S. Creating Public Value: An analytical framework for public service reform. UK, Cabinet Office, Strategy Unit. October 2002. 35p. Disponível em: https://www.academia.edu/23693003/Creating_Public_Value_An_analytical_framework_for_pub lic_service_reform. Acesso em: 5 set. 2019 
$17^{\circ}$ ERGODESIGN \& USIHC 2019

PUC-Rio, 11 a 13 de dezembro

Rio de Janeiro, RJ, Brasil $17^{\circ}$ Ergodesign - Congresso Internacional de Ergonomia e Usabilidade de Interfaces Humano Tecnológica: Produto, Informações Ambientes Construídos e Transporte

$17^{\circ}$ USIHC - Congresso Internacional de Ergonomia e Usabilidade

de Interfaces Humano Computador

AÇÃO EDUCATIVA; INSTITUTO PAULO MONTENEGRO. INAF BRASIL 2018 - Resultados preliminares. [Ana Lima e Roberto Catelli Jr., coord.]. São Paulo: Ação Educativa e Instituto Paulo Montenegro, 2018. 22p. Disponível em: http://acaoeducativa.org.br/wpcontent/uploads/2018/08/Inaf2018_Relat\%C3\%B3rio-Resultados-Preliminares_v08Ago2018.pdf Acesso em: 2 jul. 2019

LOPES, Karen M. Gross. Fatores direcionadores para a criação de valor público na adoção de serviços eletrônicos pelo cidadão. Dissertação (Mestrado em Administração) - Pontifícia Universidade Católica do Rio Grande do Sul, Porto Alegre, 2016. Disponível em: http://tede2.pucrs.br/tede2/bitstream/tede/7216/2/DIS KAREN MARIA GROSS LOPES COM PLETO.pdf.Acesso em: 12 set.2019.

LOPES, K. M.; MACADAR, M. A.; LUCIANO, E. M. Criando valor público em serviços digitais: uma proposta de conceito. Revista Eletrônica de Gestão Organizacional - GESTÃO.ORG., v. 16, Edição especial, p. 207-221, 2018. Disponível em: https://periodicos.ufpe.br/revistas/ gestaoorg/article/view/239271/31623. Acesso em: 12 set. 2019.

LOPES, K. M.; MACADAR, M. A.; LUCIANO, E. M. Valor público: o cidadão no centro da gestão pública. In: 2017 Pesquisa TIC Governo Eletrônico. São Paulo: Comitê Gestor da Internet, 2018, p. 75-83. Disponível em: https://cetic.br/media/docs/publicacoes/2/TIC _eGOV_2017_livro_eletronico.pdf. Acesso em: 12 set. 2019.

MARTINS, S.; FILGUEIRAS, L. Métodos de Avaliação de Apreensibilidade das Informações Textuais. In: Congreso Latinoamericano de la Interacción Humano-Computadora, 2007. Anais [...]. Disponível em: http://www.clihc.org/2007/papers/MetodosAvilacao_ID25_ longpaper.pdf. Acesso em: 2 jul. 2019

MENDONÇA, N. R. de S. Desburocratização Linguística: Como simplificar textos administrativos. São Paulo: Livraria Pioneira Editora, 1987.

OECD. Revisão do Governo Digital do Brasil: Rumo à Transformação Digital do Setor Público. Principais conclusões. Projeto Governo Digital OCDE. [s.I]: OECD, 2018. Disponível em: $\quad$ https://www.governodigital.gov.br/documentos-e-arquivos/digital-gov-review-brazilportugues-pdf/view. Acesso em: 12 set. 2019.

PLAIN LANGUAGE ASSOCIATION INTERNATIONAL. O que é linguagem clara?. Disponível em: https://plainlanguagenetwork.org/plain-language/o-que-e-linguagem-clara/.

Acesso em: 12 set. 2019. 
RANA, N. P.; DWIVEDI, Y. K. Citizen's adoption of an e-government system: Validating extended social cognitive theory (SCT). Government Information Quarterly, n. 32, p. 172-181, 2015.

SÃO PAULO. Orientações para Adoção de Linguagem Clara. São Paulo: Fundação Sistema Estadual de Análise de Dados - Seade, 2016. Disponível em: http://www.governoaberto.sp.gov.br/wp-content/uploads/2017/12/orientacoes para adocao linguagem clara ptBR.pdf. Acesso em: 2 jul. 2019.

SÃO PAULO (SP). Projeto de Lei 01-00226/2019. Institui a Política Municipal de Linguagem Clara nos órgãos da administração direta e indireta, e dá outras providências Câmara Municipal de São Paulo. São Paulo, SP: Câmara Municipal. [2019]. Disponível em: http://documentacao.camara.sp.gov.br/iah/fulltext/projeto/PL0226-2019.pdf. Acesso em: 2 jul. 2019

SCHRIVER, K. Plain Language in the US Gains Momentum: 1940- 2015. IEEE Transactions on Professional Communications, vol. 60, n. 4, p. 343-383, December 2017.

SILVEIRA, M. I. M. O burocratês: análise à luz de uma gramática retórica. Revista da ABRALIN, v. 7, n. 1, p. 215-258, jan./jun 2008.

UNITED NATIONS. E-Government Survey 2018: Gearing E-Government To Support Transformation Towards Sustainable And Resilient Societies. United Nations. New York, 2018. Disponível em: https://publicadministration.un.org/egovkb/Portals/egovkb/Documents/ un/2018-Survey/E-Government\%20Survey\%202018 FINAL\%20for\%20web.pdf. Acesso em: 12 set. 2019. 